\title{
Effect of a gluten free diet on osteopenia in adults with newly diagnosed coeliac disease
}

\author{
X A McFarlane, A K Bhalla, D A F Robertson
}

\begin{abstract}
Background/Aims-Calcium and vitamin D malabsorption in coeliac disease predispose to skeletal demineralisation. This study aimed to determine bone mineral density in patients studied in the first year after diagnosis of coeliac disease, and to detect changes in bone mineral density over the subsequent year.

Methods-Lumbar spine and femoral neck bone mineral density was measured in 21 adults with coeliac disease, diagnosed and started on a gluten free diet during the preceding year, with dual energy $x$ ray absorptiometry and repeated after 12 months.
\end{abstract}

Results-Bone mineral density was significantly lower in patients than in paired controls (matched for age and sex), at lumbar spine $\left(0.819 \mathrm{~g} / \mathrm{cm}^{2}\right.$ compared with $1.021 \mathrm{~g} / \mathrm{cm}^{2}, \mathrm{p}<0.001$ Wilcoxon signed rank test) and femoral neck $\left(0.663 \mathrm{~g} / \mathrm{cm}^{2}\right.$ compared with $0.794 \mathrm{~g} / \mathrm{cm}^{2}, \mathbf{p}<0.001$ ). Repeat measurement after 12 months demonstrated that patients had a significant gain in bone mineral density at lumbar spine (16.6\%/year), and femoral neck (15.5\%/year, $p<0.002$, Wilcoxon signed rank test at both sites), whereas no significant change in bone mineral density was detected in controls.

Conclusions-Treatment of coeliac disease with a gluten free diet is associated with a significant increase in bone mineral density, although patients still had lower bone mineral density than controls.

(Gut 1996; 39: 180-184)

Keywords: coeliac disease, gluten free diet, bone mineral density.

Treatment with gluten free diet in coeliac disease is associated with a rapid improvement in small bowel histology, ${ }^{1}$ nutritional deficiency, ${ }^{2}$ and symptomatic well being, but the effect of gluten free diet on the reduced bone mineral density (osteopenia) often found at diagnosis $^{3-4}$ in coeliac disease remains to be determined. Osteopenia present at the time of diagnosis of coeliac disease may be due to osteomalacia, osteoporosis or secondary hyperparathyroidism, ${ }^{5-6}$ and can be detected by noninvasive bone densitometry,,$^{3-4}$ although this technique cannot be used to identify the underlying pathology.

The measurement of bone mineral density (BMD) provides important objective information in the assessment of an individual's fracture risk, as BMD at a given skeletal site is an important determinant of fracture risk at that site, ${ }^{7-8}$ with age and predilection to falls representing additional independent factors. Thus, patients with a $\mathrm{Z}$ score (number of standard deviations by which patients BMD differs from age and sex matched normal mean BMD) of -1 have a $2 \cdot 4$-fold increase in lifetime fracture risk, and patients with $\mathrm{Z}$ score of -2 have a fivefold increase. ${ }^{9}$

In this study we have performed an initial BMD measurement on adults with coeliac disease, within 12 months of diagnosis and commencement of treatment with a gluten free diet, and repeated the measurement after one year. In addition, we have performed iliac crest bone biopsy to elucidate the underlying bone pathology in patients with skeletal symptoms at the time of diagnosis of coeliac disease.

\section{Methods}

Twenty one patients ( 14 females, seven males, average age 49.7 years, range 31.0 to 66.1 ) with newly diagnosed coeliac disease were studied. The Table shows the principal symptom leading to investigation and diagnosis of coeliac disease in each patient. The diagnosis of coeliac disease was based on clinical presentation and small intestinal biopsy in all patients prior to treatment with gluten free diet. ${ }^{1}$ All patients had a clinical and haematological response to gluten free diet. Twelve patients showed significant improvement on repeat small bowel biopsy. Two patients had persistent subtotal villous atrophy on repeat biopsy (after six and 12 months). Six patients did not have a repeat small bowel biopsy.

Three patients had significant skeletal symptoms at the time of first presentation, two of which were initially referred by their general practitioner to a rheumatology outpatients department. The first of these three patients was a 66 year old woman who presented with bone pain, muscle weakness, and a clinical, biochemical and histological picture of osteomalacia complicated by secondary hyperparathyroidism (Fig 1) prior to starting a gluten free diet. The second patient was a 59 year old woman who presented with clinical and biochemical features suggestive of osteomalacia, again confirmed on iliac crest histology, although in this case with no evidence of hyperparathyroidism. A third patient was a 43 year old man who was referred by his general practitioner to a gastroenterology outpatients department with diarrhoea, but shortly after diagnosis of coeliac disease was admitted to the rheumatology ward with bone pain and although no abnormality was detected in serum calcium, parathyroid hormone, total alkaline 
Symptoms at presentation, initial haematology, and serum biochemistry in 21 patients with newly diagnosed coeliac disease

\begin{tabular}{|c|c|c|c|c|c|c|c|c|c|c|c|}
\hline \multicolumn{10}{|c|}{ Results of investigations (units) normal range } & \multicolumn{2}{|l|}{$Z$ score } \\
\hline $\begin{array}{l}\text { Presenting } \\
\text { symptom }\end{array}$ & Sex & $\begin{array}{l}\text { Age } \\
(y)\end{array}$ & $\begin{array}{l}B M I \\
\left(\mathrm{~kg} / \mathrm{m}^{2}\right) \\
20,25\end{array}$ & $\begin{array}{l}\text { Albumin } \\
(\mathrm{g} / \mathrm{l}) \\
35,50\end{array}$ & $\begin{array}{l}H b \\
(g / d l)\end{array}$ & $\begin{array}{l}M C V \\
(f) \\
75,95\end{array}$ & $\begin{array}{l}\text { Calcium } \\
\text { (mmoll) } \\
2 \cdot 2,2 \cdot 9\end{array}$ & $\begin{array}{l}\text { Phosphate } \\
\text { (mmoll) } \\
0 \cdot 8,1 \cdot 5\end{array}$ & $\begin{array}{l}A L P \\
(I U /) \\
21,92\end{array}$ & $\begin{array}{l}\text { Spine } \\
-2,2\end{array}$ & $\begin{array}{l}H_{-2}, 2 \\
\end{array}$ \\
\hline \multirow{5}{*}{$\begin{array}{l}\text { Anaemia } \\
(n=5)\end{array}$} & $\mathrm{F}$ & $45 \cdot 5$ & $22 \cdot 1$ & 44 & $11 \cdot 4$ & $108 \cdot 6$ & $2 \cdot 19$ & $0 \cdot 89$ & 49 & $0 \cdot 39$ & -0.44 \\
\hline & & $47 \cdot 4$ & $22 \cdot 0$ & $\begin{array}{l}44 \\
39\end{array}$ & $9 \cdot 8$ & $68 \cdot 8$ & $2 \cdot 16$ & 0.99 & 88 & $-1 \cdot 81$ & -0.41 \\
\hline & & $49 \cdot 4$ & $22 \cdot 6$ & 33 & $8 \cdot 2$ & $64 \cdot 9$ & 2.06 & 0.75 & 142 & $-2 \cdot 17$ & -0.86 \\
\hline & $\mathbf{M}$ & $31 \cdot 0$ & $34 \cdot 2$ & 48 & 11.5 & $80 \cdot 7$ & $2 \cdot 14$ & $1 \cdot 16$ & 62 & $-1 \cdot 86$ & -0.95 \\
\hline & & $43 \cdot 6$ & 25.0 & 41 & 9.9 & $72 \cdot 5$ & $2 \cdot 13$ & $1 \cdot 19$ & 90 & 1.69 & -0.99 \\
\hline \multirow{4}{*}{$\begin{array}{l}\text { Average } \\
\text { Bone pain } \\
(n=3)\end{array}$} & & 43.4 & $25 \cdot 2$ & 41 & $10 \cdot 2$ & $79 \cdot 1$ & $2 \cdot 14$ & 1.00 & $86 \cdot 2$ & -0.75 & -0.73 \\
\hline & $\mathbf{F}$ & 58.7 & 21.0 & 35 & $12 \cdot 4$ & $94 \cdot 1$ & $2 \cdot 18$ & 0.97 & 126 & $-2 \cdot 58$ & $-3 \cdot 52$ \\
\hline & & $66 \cdot 1$ & $30 \cdot 6$ & 46 & $12 \cdot 8$ & $113 \cdot 5$ & $2 \cdot 25$ & 0.99 & 289 & $-2 \cdot 85$ & $-1 \cdot 48$ \\
\hline & $\mathbf{M}$ & $43 \cdot 0$ & $22 \cdot 3$ & 42 & $12 \cdot 0$ & $71 \cdot 7$ & $2 \cdot 31$ & $1 \cdot 25$ & 85 & $-3 \cdot 47$ & $-1 \cdot 04$ \\
\hline \multirow{11}{*}{$\begin{array}{l}\text { Average } \\
\text { Diarrhoea } \\
(n=10)\end{array}$} & & 55.9 & $24 \cdot 6$ & 41 & $12 \cdot 4$ & $93 \cdot 1$ & $2 \cdot 25$ & 1.07 & $166 \cdot 7$ & $-2 \cdot 97$ & $-2 \cdot 01$ \\
\hline & F & $36 \cdot 3$ & $23 \cdot 6$ & 41 & 11.5 & 92 & $2 \cdot 19$ & 1.09 & 58 & $-2 \cdot 76$ & $-3 \cdot 36$ \\
\hline & & 37.5 & $19 \cdot 1$ & 40 & $10 \cdot 7$ & $68 \cdot 2$ & $2 \cdot 07$ & $1 \cdot 24$ & 141 & $-2 \cdot 73$ & -2.98 \\
\hline & & $47 \cdot 0$ & $21 \cdot 8$ & 42 & 13.5 & $97 \cdot 5$ & $2 \cdot 21$ & $1 \cdot 13$ & 45 & $-0 \cdot 16$ & $-1 \cdot 01$ \\
\hline & & $48 \cdot 8$ & $21 \cdot 5$ & 41 & $8 \cdot 3$ & $66 \cdot 3$ & $2 \cdot 2$ & $1 \cdot 37$ & 104 & $-2 \cdot 15$ & -1.65 \\
\hline & & $53 \cdot 1$ & 23.9 & 38 & $15 \cdot 5$ & 91 & $2 \cdot 18$ & 1.09 & 58 & $-0 \cdot 47$ & $-1 \cdot 48$ \\
\hline & & $61 \cdot 8$ & $21 \cdot 8$ & 31 & 13.1 & $85 \cdot 2$ & $2 \cdot 14$ & 0.97 & 178 & -0.99 & -0.99 \\
\hline & $\mathbf{M}$ & $47 \cdot 9$ & $27 \cdot 0$ & 30 & $12 \cdot 1$ & $97 \cdot 3$ & 2.01 & 0.93 & 152 & -1.89 & $-1 \cdot 13$ \\
\hline & & $55 \cdot 6$ & $22 \cdot 6$ & 34 & 13.0 & $110 \cdot 1$ & $2 \cdot 2$ & 0.81 & 126 & $-2 \cdot 01$ & -1.9 \\
\hline & & $57 \cdot 0$ & $19 \cdot 1$ & & $10 \cdot 7$ & 132.5 & $2 \cdot 15$ & $1 \cdot 12$ & 79 & $-2 \cdot 01$ & -0.48 \\
\hline & & $64 \cdot 9$ & 23.9 & 35 & $14 \cdot 4$ & 115.8 & $2 \cdot 14$ & $1 \cdot 18$ & 131 & $-1 \cdot 67$ & -0.79 \\
\hline Average & & 51 . & $22 \cdot 4$ & $37 \cdot 6$ & $12 \cdot 3$ & 95.6 & $2 \cdot 15$ & 1.093 & $107 \cdot 2$ & $-1 \cdot 68$ & -1.58 \\
\hline Weight loss & F & $43 \cdot 1$ & $25 \cdot 2$ & 39 & $11 \cdot 0$ & 83 & $2 \cdot 22$ & 1.07 & 50 & $-1 \cdot 44$ & -1.9 \\
\hline and malaise & & 53.9 & $21 \cdot 1$ & 43 & $15 \cdot 0$ & $92 \cdot 8$ & $2 \cdot 37$ & $1 \cdot 22$ & 91 & -0.87 & -1.69 \\
\hline$(n=3)$ & & & $22 \cdot 3$ & 42 & $13 \cdot 1$ & $99 \cdot 4$ & $2 \cdot 18$ & 1.01 & 75 & $-0 \cdot 22$ & $-1 \cdot 48$ \\
\hline Average & & 49 & $22 \cdot 9$ & $41 \cdot 3$ & 13.0 & $91 \cdot 7$ & $2 \cdot 26$ & $1 \cdot 10$ & $72 \cdot 0$ & -0.84 & -1.69 \\
\hline Overall average & & $49 \cdot 7$ & $23 \cdot 5$ & $39 \cdot 4$ & 11.9 & $90 \cdot 8$ & $2 \cdot 18$ & 1.07 & $105 \cdot 7$ & $-1 \cdot 53$ & $-1 \cdot 45$ \\
\hline
\end{tabular}

(BMI= body mass index, $\mathrm{MCV}=$ mean corpuscular volume, $\mathrm{Hb}=$ haemoglobin, $\mathrm{ALP}=$ alkaline phosphatase).

phosphatase or 25 dydroxy-vitamin $\mathrm{D}$, iliac crest bone biopsy revealed osteomalacia. In addition to gluten free diet, these three patients with histologically confirmed osteomalacia were treated with oral calcitriol $(1,25$ dihydroxyvitamin $\mathrm{D}, 1000 \mu \mathrm{g}$ orally daily).

The remaining 18 patients were referred to a gastroenterology outpatients department in a district general hospital because of anaemia (five patients), diarrhoea (10 patients), or weight loss and malaise (three patients) (Table). They had no symptoms of skeletal pathology, and were treated only with gluten free diet, and no vitamin, mineral or hormone supplements. Gluten free diet was started and compliance monitored by a dietitian. Of these 18 , the patient with the lowest BMD, a 36 year old woman, had a tetracycline double labelled bone biopsy ${ }^{10}$ after commencing a gluten free diet. This biopsy showed osteoporosis, with disruption of trabecular bone architecture, and evidence of low bone turnover.

A total of 137 healthy adult volunteers from the local Bath population have had serial bone mineral density measurements in our Clinical Measurement laboratory. For each patient with coeliac disease a single unique control of the appropriate sex was selected from this database, based on best match for age. Female patients and their controls were also matched for menopausal status. Weight (kilograms) and height (metres) were recorded at the time of each bone scan in patients and controls. Body mass index $\left(\mathrm{kg} / \mathrm{m}^{-2}\right)$ was calculated with the patients weight $(\mathrm{kg})$ divided by the square of their height $\left(\mathrm{m}^{2}\right)$. Blood tests in all patients included haemoglobin, mean corpuscular volume, serum calcium, phosphate, and alkaline phosphatase (Table).

BMD was measured in patients within one year of diagnosis of coeliac disease (average 0.5 years) and also in healthy controls with an Hologic QDR dual energy $x$ ray absorptiometer, at the lumbar spine (L1-4) and the femoral neck on entry to the study and again after 12 months. The BMD is expressed as an absolute value $\left(\mathrm{g} / \mathrm{cm}^{2}\right)$, and as a $Z$ score (number of standard deviations by which patient or matched control BMD differs from the $B M D$ of an age and sex matched reference population). The percentage change in BMD per year was calculated as the difference in the $\mathrm{BMD}$ at 12 months compared with the BMD at the start of the study, and expressed as a percentage of the initial BMD. The reference population from which the $\mathrm{Z}$ scores are

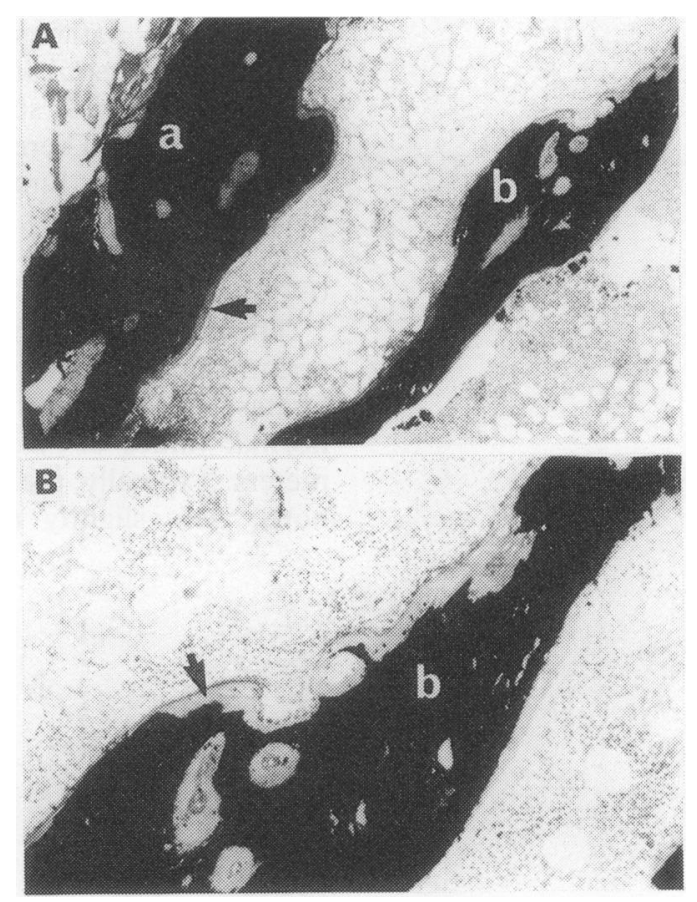

Figure 1: Iliac crest bone biopsy in 66 year old woman with newly diagnosed coeliac disease. Plastic embedded undecalcified section $(A)$ : original magnification $\times 40$, $(B)$ : original magnification $\times 100$, stained with toluidine blue (calcified bone is stained black). This section

demonstrates features of osteomalacia (extensive and thick osteoid matrix lining the surface of the thin cortical and trabecular bone). a: bone cortex; b: bone trabeculum; $\rightarrow$ : unmineralised osteoid matrix. 
derived, is that provided by the American manufacturer, and is based on measurements in 2000 normal American adults. We have demonstrated the validity of the Hologic reference population for the Bath population; from the database of 137 health adult volunteers average lumber BMD was $105 \cdot 8 \%$ and $97 \cdot 8 \%$ of the BMD of Hologic normal women and men respectively, and average femoral neck BMD was $98 \cdot 7 \%$ and $95 \cdot 2 \%$ of Hologic normal women and men respectively. The precision error (longitudinal coefficient of variation based on daily measurement of the standard Hologic lumbar spine phantom) of the instrument over the duration of the study was $0 \cdot 49 \%$.

The statistical significance of differences between paired data was calculated using Wilcoxon's signed rank test. Correlation coefficient was determined using Spearman's rank correlation. The $95 \%$ confidence intervals are based on Student's $t$ distribution.

\section{Results}

The average lumbar spine $\mathrm{BMD}$ of patients was only $80.5 \%$ (range $65 \%$ to $97 \%$ ) of the BMD of matched healthy controls. The average femoral neck BMD of patients was only $84.2 \%$ (range $56 \%$ to $106 \%$ ) of the BMD of matched healthy controls. The lumbar spine BMD in patients $\left(0.819 \mathrm{~g} / \mathrm{cm}^{2} ; 95 \%\right.$ CI 0.749 to $0.888 \mathrm{~g} / \mathrm{cm}^{2}$ ) was significantly lower $(\mathrm{p}<0.001)$ than controls $\left(1.021 \mathrm{~g} / \mathrm{cm}^{2} ; 95 \%\right.$ CI 0.948 to $1.094 \mathrm{~g} / \mathrm{cm}^{2}$ ). Femoral neck BMD in patients $\left(0.663 \mathrm{~g} / \mathrm{cm}^{2} ; 95 \%\right.$ CI 0.615 to $0.710 \mathrm{~g} / \mathrm{cm}^{2}$ ) was significantly lower $(\mathrm{p}<0.001)$ than controls $\left(0.794 \mathrm{~g} / \mathrm{cm}^{2} ; 95 \%\right.$ CI 0.747 to $0.841 \mathrm{~g} / \mathrm{cm}^{2}$ ).

The three patients with osteomalacia had among the lowest $Z$ scores at the lumbar spine, but intermediate $Z$ scores at the femoral neck (Figs 2 and 3). There was a closer correlation between BMD at lumbar spine and at femoral neck in normal adults $(r=0.81,95 \%$ CI 0.59 to $0.92)$ than in patients $(r=0.47,95 \% \mathrm{CI} 0.05$ to $0 \cdot 75$ ).

There were frequent minor abnormalities of serum calcium, phosphate, and alkaline phosphatase (Table), only four (19\%) patients had normal values of all three biochemical parameters. Typically, the calcium or phosphate, or both, were slightly reduced or the alkaline

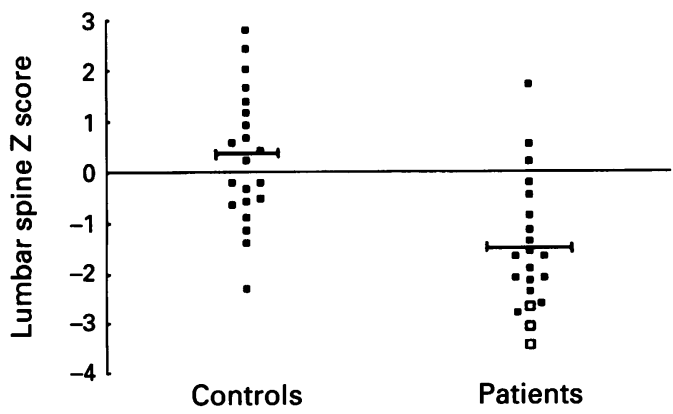

Figure 2: Lumbar spine $Z$ score is significantly lower in 21 patients with newly diagnosed coeliac disease $(p<0.01$, Wilcoxon rank sum test) than in 21 healthy controls matched for age, sex, weight, and height. (Three patients with osteomalacia are represented by open boxes.)

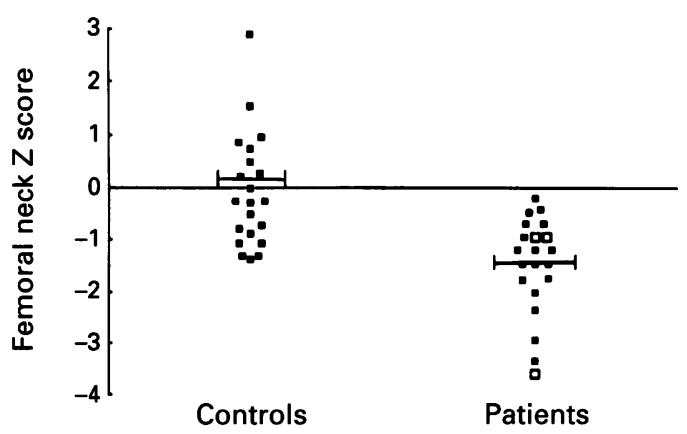

Figure 3: Femoral neck $Z$ score is significantly lower in 21 patients with newly diagnosed coeliac disease $(p<0.01$, Wilcoxon rank sum test) than in 21 healthy controls matched for age, sex, weight, and height. (Three patients with osteomalacia are represented by open boxes.)

phosphatase increased. There was no significant difference $(p>0 \cdot 10)$ in weight, height or body mass index in patients compared with controls.

Serial measurements showed no significant change in BMD ( $>>0 \cdot 10)$ over the 12 months of follow up at either lumbar spine $(-0.007$ $\mathrm{g} / \mathrm{cm}^{2} /$ year, $95 \%$ CI: -0.020 to $+0.006 \mathrm{~g} / \mathrm{cm}^{2} /$ year) or femoral neck $\left(+0.005 \mathrm{~g} / \mathrm{cm}^{2} /\right.$ year, $95 \%$ CI: -0.010 to $+0.021 \mathrm{mg} / \mathrm{cm}^{2} /$ year) in healthy controls. In patients however there was a significant gain in BMD at lumbar spine $\left(+0.047 \mathrm{~g} / \mathrm{cm}^{2} /\right.$ year, $95 \% \mathrm{CI}:+0.024$ to $+0.071 \mathrm{~g} / \mathrm{cm}^{2} /$ year, $\left.\mathrm{p}<0.001\right)$ and at femoral neck $\left(+0.033 \mathrm{~g} / \mathrm{cm}^{2} /\right.$ year, $95 \%$ CI: +0.016 to $+0.050 \mathrm{~g} / \mathrm{cm}^{2} /$ year, $\left.\mathrm{p}<0.002\right)$. Similarly, when expressed as a $Z$ score there was no significant change in BMD Z score $(p>0 \cdot 10)$ over the 12 months of follow up at either lumbar spine (change in $\mathrm{Z}$ score: $+0.001 /$ year, $95 \% \mathrm{CI}$ : -0.11 to $+0.12 /$ year) or femoral neck $(+0.06 /$ year, $95 \% \mathrm{CI}:-0 \cdot 11$ to $+0 \cdot 25 /$ year $)$ in healthy controls. In patients however there was a significant gain in $\mathrm{BMD} \mathrm{Z}$ score at lumbar spine (change in $\mathrm{Z}$ score: $+0.47 /$ year, $95 \% \mathrm{CI}$ : +0.25 to +0.68 /year, $\mathrm{p}<0.001)$ and at femoral neck $(+0.37 /$ year, $95 \%$ CI: +0.21 to $+0.53 /$ year, $\mathrm{p}<0.002)$.

The absolute increase of BMD in patients was equivalent to an increase at the lumbar spine of $+6.6 \%$ /year $(95 \%$ CI: $+3 \cdot 1$ to $+10 \cdot 1 \% /$ year, Fig 4$)$ and at the femoral neck of $5 \cdot 5 \% /$ year ( $95 \%$ CI: $+2 \cdot 8$ to $+8 \cdot 1 \% /$ year). Again, this contrasts with no significant change in BMD over 12 months in healthy controls at

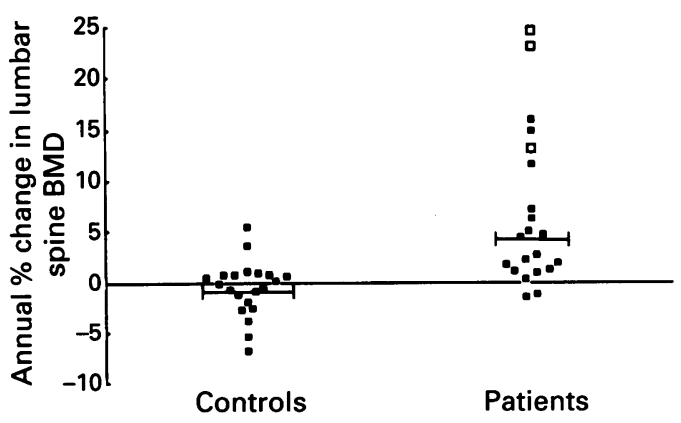

Figure 4: Twenty one healthy adults show no significant change in $B M D(p>0 \cdot 10$, Wilcoxon signed rank test) at lumbar spine over 12 months, whereas 21 patients with newly diagnosed coeliac disease have a significant gain in $B M D(p<0.01)$. (Three patients with osteomalacia are represented by open boxes.) 


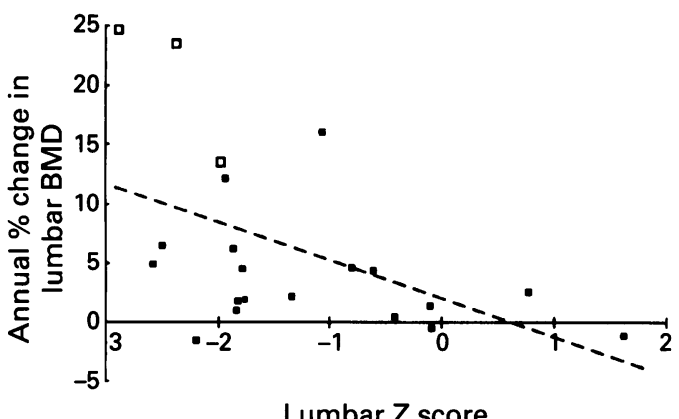

Lumbar Z score

Figure 5: Rate of change of BMD at lumbar spine in patients is negatively correlated with lumbar spine $Z$ score ( $\mathrm{r}=-0.51, p<0.05$. Spearman's rank correlation). Patients with the lowest BMD have the greatest percentage change in BMD over the 12 month interval. (Three patients with osteomalacia are represented by open boxes.)

lumbar spine (mean $-0 \cdot 7 \%, 95 \%$ CI: $-1 \cdot 9 \%$ to $+0.5 \%$ ) or at femoral neck (mean $+0.9 \%$, $95 \%$ CI: $-0 \cdot 8 \%$ to $+2 \cdot 7 \%$ ). In patients there was a strong correlation between the rate of change in $\mathrm{BMD}$ (\%/year) at lumbar spine and the rate of change at the femoral neck $(r=0 \cdot 76$, $\mathrm{p}<0.001$ ).

Patients with osteomalacia had among the greatest gains in BMD at both lumbar spine and femoral neck over the 12 months. Rates of change of BMD at both lumbar spine and femoral neck were negatively correlated with lumbar spine $\mathrm{Z}$ score $(r=0.51, \mathrm{p}<0.05$ at both lumbar spine and femoral neck, Fig 5), the most severely osteopaenic patients having the most rapid gain in $\mathrm{BMD}$, and patients with normal initial BMD demonstrating only small increases in BMD. There was a greater weight gain over the 12 months in patients $(+4.5 \%$, $95 \%$ CI: $+2 \cdot 2$ to $+6 \cdot 3 \%$ ), than controls $(+1 \cdot 1 \%, 95 \% \mathrm{CI}:+0 \cdot 1$ to $+2 \cdot 3 \%)$. In patients there was no correlation between change in weight and change in BMD.

As a result of these increases over 12 months, the lumbar spine BMD of patients, expressed as a percentage of the lumbar spine BMD of their paired control, increased from $80.5 \%$ at the beginning of the study, to $86.1 \%$ after 12 months treatment with a gluten free diet. The equivalent increase at femoral neck was from $84 \cdot 2 \%$ to $87 \%$. Despite this improvement of BMD in patients compared with controls, BMD after 12 months was still significantly lower at lumbar spine $(\mathrm{p}<0.001)$ in patients $\left(0.863 \mathrm{~g} / \mathrm{cm}^{2}, 95 \%\right.$ CI 0.802 to $\left.0.925 \mathrm{~g} / \mathrm{cm}^{2}\right)$ compared with controls $(1.014$ $\mathrm{g} / \mathrm{cm}^{2}, 95 \%$ CI 0.939 to $1.088 \mathrm{~g} / \mathrm{cm}^{2}$ ) and at femoral neck $(\mathrm{p}<0.002)$ in patients $(0.693$ $\mathrm{g} / \mathrm{cm}^{2}, 95 \%$ CI 0.650 to $0.736 \mathrm{~g} / \mathrm{cm}^{2}$ ) compared with controls $\left(0.799 \mathrm{~g} / \mathrm{cm}^{2}, 95 \%\right.$ CI 0.759 to $\left.0.840 \mathrm{~g} / \mathrm{cm}^{2}\right)$.

Patients $(n=13)$ whose initial BMD measurement was less than six months after commencing gluten free diet had significant increase in BMD at lumbar spine and femoral neck after 12 months (Wilcoxon signed rank test $\mathrm{p}<0.01$ at both sites), whereas the patients whose first BMD measurement was six to 12 months after commencing gluten free diet showed no significant increase at either site $(\mathrm{p}>0 \cdot 10)$.

\section{Discussion}

These results confirm previously reported findings of low BMD in patients at the time of presentation of coeliac disease. ${ }^{3411} 12$ In addition there is evidence of the beneficial effect of gluten free diet on bone mineral density in patients in the early stages of treatment. Three patients had histological evidence of osteomalacia and in one of these patients there was severe secondary hyperparathyroidism. Bone biopsy in a fourth patient confirmed osteoporosis.

Mora et al ${ }^{13}$ demonstrated a gain of BMD in children with coeliac disease given a gluten free diet, in whom an increase in BMD would be expected with growth. A previous study of the effect of gluten free diet on BMD in adults with newly diagnosed coeliac disease ${ }^{4}$ failed to show any gain in BMD during the first year of dietary treatment, however BMD was measured using the older and less precise technique of single photon absorptiometry, and this technique may have been too insensitive to detect the relatively small change in BMD.

The gain of BMD at both lumbar spine and femoral neck was apparent in almost all of the patients in our study, ranging from the modest increases in most patients, to the dramatic increases seen in patients with osteomalacia. The lower bone density in patients than controls at the beginning of the study and the gains of $\mathrm{BMD}$ at both lumbar spine and femoral neck were still significant even if the analysis excluded the three patients who had osteomalacia demonstrated at bone biopsy. Patients with osteomalacia were particularly susceptible to osteopaenia at the lumbar spine and this may be because of the high proportion of trabecular bone at this site, which therefore has a higher surface to volume ratio and therefore greater metabolic activity than the femoral neck, which has a greater proportion of cortical bone. ${ }^{14}$

At any given point in time there is a reversible mineral deficit ${ }^{15}$ of approximately $1.5 \%$ of total bone mineral, equivalent to the fraction of the normal skeleton undergoing remodelling at that time. If bone turnover increases by $50 \%$, as may occur due to an increase in parathyroid hormone, ${ }^{15}$ then the reversible mineral deficit will increase from $1.5 \%$ to $2.3 \%$, detected as a decrease in BMD compared with controls.

There is evidence to suggest that initially high bone turnover in untreated coeliac disease returns to normal after treatment with a gluten free diet. ${ }^{46} \mathrm{We}$ propose that the demonstrated increase in BMD after commencing a gluten free diet is due to reduction of the increased bone turnover in patients with untreated coeliac disease and consequent decrease in the reversible mineral deficit towards normal. A similar effect accounts for the initial increase in BMD on commencing hormone replacement therapy in postmenopausal women with increased bone turnover. In coeliac disease increased bone turnover would possibly be driven by the secondary hyperparathyroidism due to a negative calcium balance. ${ }^{6}$ Given this proposed mechanism it is not likely that bone 
density would increase for much longer than the duration of this study, and it is likely that the maximal improvement would be apparent by two years after commencing a gluten free diet. This result is supported by our finding of a significant gain in BMD only in the subgroup of patients on gluten free diet for less than six months at the start of the study. In the patients with osteomalacia the mechanism of increase in $\mathrm{BMD}$ is the re-mineralisation of the large volume of unmineralised osteoid matrix, as a consequence of improved calcium and vitamin D status. ${ }^{6}$

In our study, despite the significant gain in BMD on treatment with gluten free diet for 12 months, there was still residual osteopenia; patients with coeliac disease still had lumbar spine and femoral neck BMD only $86 \%$ and $87 \%$ respectively, of that of age and sex matched normal controls. The optimal timing for BMD measurements in coeliac disease remains to be established, but an initial measurement at the time of diagnosis, followed by repeat measurement 12 months later will detect patients with persistent osteopenia. All patients with newly diagnosed coeliac disease need careful dietary advice, to emphasise compliance with a gluten free diet and an adequate calcium and vitamin $\mathrm{D}$ intake, if necessary with calcium supplementation. There is evidence that calcium intake is reduced in some subjects with coeliac disease, ${ }^{11}$ and that calcium malabsorption persists despite compliance with a gluten free diet. ${ }^{16-17}$ In patients who have persistent osteopenia further measures may need to be taken. In women who are approaching the menopause hormone replacement therapy should be considered, and with patients with established osteoporotic fractures bisphosphonates may be offered. Patients with coeliac disease should be advised of the often silent effects of untreated coeliac disease on the skeleton, and of the importance of adhering to a gluten free diet, even if there are no gastrointestinal or skeletal symptoms.

This study was supported by grants from the Coeliac Trus (United Kingdom) and National Osteoporosis Society (United Kingdom).

1 Trier JS. Celiac sprue. In: Sleisenger $\mathrm{MH}$, Fordtran JF. Gastrointestinal diseases. Pathophysiology, diagnosis, man-
agement. Philadelphia: W B Saunders, 1993: 1078-96.

2 Benson GD, Kowlessar OD, Sleisenger MH. Adult coeliac disease with emphasis on the response to the gluten free disease with emphasis on the
diet. Medicine 1964; 43: 1-40.

3 Molteni N, Caraceni MP, Bardella MT, Ortolani S, Gandolini GG, Bianchi P. BMD in adult coeliac patients and the effect of a gluten free diet from childhood. $A m \mathcal{F}$ Gastroenterol 1990; 85: 51-3.

4 Caraceni MP, Molteni N, Bardella MT, Ortolani S, Nogara A, Bianchi PA. Bone and mineral metabolism in adult coeliac disease. Am 7 Gastroenterol 1988; 83: 274-7.

5 De Boer WA, Tytgat GN. A patient with osteomalacia as a single presenting symptom of gluten sensitive enteropathy. Intern Med 1992; 232: 81-5.

6 pathy. Intern Med 1992; 232: 81-5. Calcium metabolism and bone pathology in adult coeliac disease. $Q f M e d$ 1970; 39: 82-113.

7 Nordin BEC. Editorial. The definition and diagnosis of osteoporosis. Calif Tissue Int 1987; 40: 57-8.

8 Kanis JA, Melton J, Christiansen C, Johnston CC, Khaltev N. Perspective: The diagnosis of osteoporosis. $\mathcal{f}$ Bone Miner Res 1994; 9: 1137-41.

9 Cummings SR, Black DM, Nevitt MC, Browner W, Cauley $\mathrm{J}$, Ensrud $\mathrm{K}$, et al. Bone density at various sites for prediction of hip fractures. The study of osteoporotic fractures research group. Lancet 1993; 341: 72-5.

10 Boyce BF. Uses and limitations of bone biopsy in management of metabolic bone disease. Ballieres Clin Endocrinol Metab 1988: 2: 31-57.

11 McFarlane XA, Bhalla AK, Reeves DE, Morgan LM Robertson DAF. Osteoporosis in treated adult coeliac Robertson DAF. Osteoporosi
disease. Gut 1995; 36: 710-4.

12 Gonzalez D, Mazure R, Mautalen C, Vazquez H, Bai J. Body composition and bone mineral density in treated and untreated patients with coeliac disease. Bone 1995; 16: 231-4.

13 Mora S, Weber G, Barera G, Bellini G, Bellini A, Pasolini $\mathrm{D}$, et al. Effect of gluten free diet on bone mineral content in growing patients with coeliac disease. Am $\mathcal{F}$ Clin Nutr 1993; 57: 224-8.

14 Avioli LV, Lindsay R. The female osteoporotic syndrome(s). In: Avioli LV, Krane SM. Metabolic bone disease and clinically related disorders. Philadelphia: W B disease and clinically related

15 Eriksen EF. Normal and pathological remodelling of human trabecular bone: three dimensional reconstruction of the remodelling sequence in normal and in metabolic bone disease. Endocr Rev 1986; 7: 379-408.

16 Staun M, Jarnum S. Measurement of the 10,000 molecular weight calcium binding protein in small intestinal biopsy specimens from patients with malabsorption syndromes. Scand $\mathcal{F}$ Gastroenterol 1988; 23: 827-32.

17 McFarlane XA, Bhalla AK, Robertson DAF. Intestina strontium absorption and bone mineral density in treated adult coeliac disease. Gastroenterology 1995; 108: A739. 